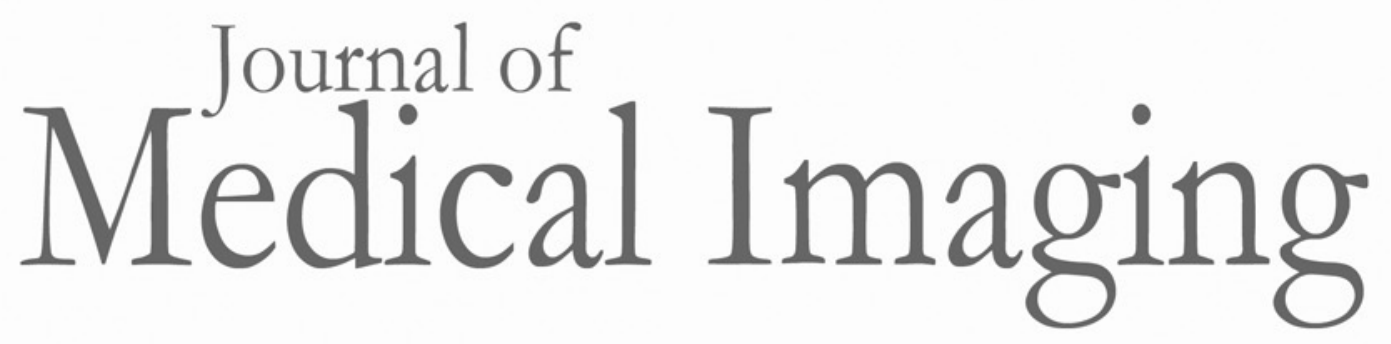

Medicallmaging.SPIEDigitalLibrary.org

\title{
Pioneers in Medical Imaging Series
}

\author{
Maryellen L. Giger
}

\section{SPIE.}




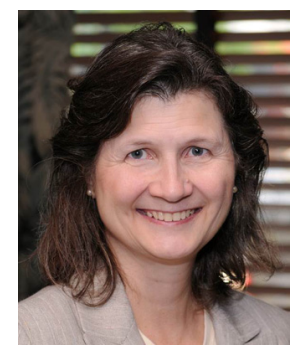

\section{Pioneers in Medical Imaging Series}

With this third issue of the Journal of Medical Imaging (JMI), we welcome our first special section, a "Pioneers in Medical Imaging" section that honors Robert F. Wagner, an outstanding scientist who has influenced many of us. I greatly thank our two guest editors, Kyle Myers and Weijie Chen, who have graciously given outstanding efforts and time to creating this issue.

Please enjoy the moving and enlightening guest editorial.

Maryellen L. Giger

Editor-in-Chief 